\title{
Relações de gênero e ruralidade nos projetos vitais e noções de si de jovens mulheres ${ }^{\star}$
}

\author{
Adolfo Pizzinato, ${ }^{I} \star \star ~ C r i s t i a n o ~ H a m a n n,{ }^{I}$ Rodrigo de Oliveira Machado, ${ }^{I I}$ Marlene Neves Strey ${ }^{I}$ \\ ${ }^{I}$ Pontifícia Universidade Católica do Rio Grande do Sul, Porto Alegre, RS, Brasil \\ II Universitat Autònoma de Barcelona, Barcelona, Espanha
}

\begin{abstract}
Resumo
O presente artigo apresenta os resultados de uma pesquisa qualitativa com 48 jovens mulheres do meio rural do Rio Grande do Sul, focando aspectos do protejo vital e marcadores identitários presentes na construção dos mesmos. A aproximação metodológica consistiu de uma combinação entre entrevistas narrativas de caráter biográfico e uma proposta de fotocomposição, ambas com roteiro de produção semiestruturada. Os resultados indicam que as relações comunitárias de ruralidade e de gênero são importantes marcos dos projetos vitais dessas jovens, que pendem entre leituras tradicionais dos papéis de gênero e possibilidades subversivas do feminino, em um processo narrativo dialógico.
\end{abstract}

Palavras-chave: juventude; gênero; ruralidade.

\section{Gender and rurality relations in vital projects and self-notions of young women}

\begin{abstract}
This article presents the results of a qualitative study with 48 young women from rural areas of Rio Grande do Sul (Brazil), focusing on aspects of them life's project and identity markers present in their projects. The methodological approach consisted of a combination of biographical narrative interviews and a proposal auto photographical composition, with subsequent semi-structured interviews. The results indicate that the community relations rurality and gender are important landmarks of the vital projects of these young people that hang between traditional readings of gender roles and subversive possibilities of the female, in a dialogic narrative process.
\end{abstract}

Keywords: youth; gender; rurality.

\section{Introdução}

A análise de discursos sobre o "ser/estar" na atualidade se traduz em ferramenta importante para o entendimento da construção das identidades de agora. Tais apreciações podem se dirigir a discursos de uma população específica, como é o caso deste artigo, em que se discute quais são os processos de significação de si de jovens mulheres e se vislumbra a repercussão desses significados nas suas vidas. $\mathrm{O}$ presente artigo traz como proposta apresentar e discutir as significações de alguns marcadores identitários (especialmente gênero e lugar) através de narrativas de jovens mulheres do meio rural no que concerne a suas trajetórias de vida e projetos de futuro.

Dentro do campo das ciências humanas, sobretudo no âmbito da psicologia, alguns autores auxiliaram na construção atual da compreensão dos significados identitários e sua relação com a cultura. De acordo com a análise de Mendoza et al. (2009), um dos pioneiros desta perspectiva epistemológica teria sido Vygotsky, em cuja obra o processo de significação, e de negociação entre indivíduo e cultura, recebe primordial ênfase. Posteriormente, derivado da mesma matriz, Jerome Bruner discute a necessidade de priorizar o significado como mediador entre o homem e a cultura, ao mesmo tempo em que sinaliza a

\footnotetext{
${ }^{\star} \mathrm{O}$ presente artigo é um recorte do projeto: "Etnicidade e ruralidade na construção de trajetórias educacionais e projetos vitais de jovens mulheres", Edital 07/2011 CNPq.

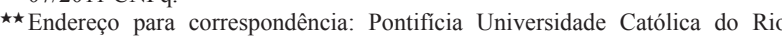
Grande do Sul, Faculdade de Psicologia. Av. Ipiranga 6681, Prédio 11, sala 930 - Partenon. CEP: 90619900 - Porto Alegre, RS - Brasil. E-mail: adolfopizzinato@hotmail.com,chamann13@hotmail.com,rodrigo.psicopuc@gmail. com, streymn@pucrs.b
}

implicação destes na formação cognitiva dos eus. Na esteira desta discussão, Keneth Gergen, por sua vez, ganha destaque ao apontar que o significado deve sempre ser visto junto ao contexto em que é produzido e ao momento histórico em que está situado. Essa concepção, precursora do construcionismo, acarreta na aproximação do pesquisador do local em que a realiza e daqueles que dela participam, além de delimitá-lo temporalmente (ARCILA MENDOZA, et al., 2010).

Gergen (1996) partindo dessa concepção de um "eu" desnaturalizado aponta a contraposição entre um "eu romântico" (caracterizado pelas paixões, os sentimentos e a moralidade) e um "eu moderno" (caracterizado pela razão, a objetividade e o controle das emoções). O autor sustenta que nosso tempo está construindo um "eu pós-moderno", produto das novas formas de relação possibilitadas e intensificadas pelas mudanças tecnológicas que levam a uma "deslocalização". Este "eu saturado" recebe as demandas de diferentes relações frente àquelas em que emergem "múltiplos eus" cujas vozes não são necessariamente harmônicas. A dicotomia entre um eu fortemente coeso pela moral ("eu romântico") ou pela razão ("eu moderno"), claramente diferenciados do "outro", é desdobrada no "eu pós-moderno" por uma "polifonia" de vozes próprias e alheias que se entrecruzam.

Dentro da psicologia atual, novas abordagens sobre os processos identitários vêm ganhando espaço. Exemplo disso é a proposta de Hermans (2001), definida como "self dialógico", conceito que dissolve o conceito de um 
eu estruturado, centralizado e de difícil mudança e postula a ideia de um eu descentralizado, narrativo e em movimento, isto é, o self passa a se caracterizar pelo constante processo de mudança entre as diferentes posições que o "eu" assume (i-positions) (SANTOS; GOMES, 2010). Esta perspectiva dialógica, fortemente influenciada pela virada linguística em ciências sociais, considera que a criação de significados ocorre a partir da comunicação e da relação existente entre um centro, o "Eu", e a periferia, que se refere a tudo aquilo que não faz parte desse centro, o "Outro".

Esta construção teórica se inspira também na vertente da psicologia discursiva e na sua ênfase narrativa. Embora autores como Brockmeier e Harré (2003, p. 526) salientem a ampla variedade de formas narrativas existentes, eles a definem como o "conjunto de estruturas linguísticas e psicológicas transmitidas cultural e historicamente, delimitadas pelo nível do domínio de cada indivíduo e pela combinação de técnicas sócio comunicativas e habilidades cognitivas". Mesmo que o repertório narrado seja local, o cenário cultural amplo no qual ele se inscreve é repleto de ordens discursivas fundamentais que situam o autor que conta, quando o faz (dimensão temporal), onde (dimensão espacial) e para qual audiência está dirigida a ação de narrar.

Esse contexto discursivo circunscreve as narrativas sobre diversas formas de ser e fazer na sociedade, permitindo, por exemplo, pensar a juventude como uma construção social atravessada por diversos aspectos macroestruturais, e organiza os discursos e práticas sobre determinada etapa da vida. Na tentativa de estabelecer uma linha de discussão que contemple a dialogia nos processos de definição da juventude, Lopes de Oliveira (2006) resgata a construção do conceito de adolescência no campo da psicologia e estabelece uma discussão orientada pelo conceito de self dialógico, defendendo uma possibilidade de abordar este período do desenvolvimento em que se entrecruzam diferentes níveis temporais; o retrospectivo da infância e o prospectivo da vida adulta.

A juventude pode ser entendida como uma fase de transição, que supõe importantes modificações, considerada um momento de preparação para a vida adulta. Entretanto, as diferentes possibilidades de "ser" dos jovens são circunscritas por aspectos sócio-históricos, culturais e territoriais, e demandam eleger metas, sonhos, formação de um núcleo familiar, projetos acadêmicos e profissionais como temáticas-chave para o ingresso à adultez.

Culturalmente, a juventude ocidental passa a ser reconhecida discursivamente através de um processo de naturalização de diversos fatores, comumente delimitados a partir de uma perspectiva biologizante, posicionado em relação à adolescência, onde o gênero e a sexualidade seriam pontos fundamentais dessa transição. Em uma reflexão mais específica sobre este aspecto, podemos verificar que as transformações hormonais e corporais se fazem presentes em muitos dos estudos produzidos sobre a juventude, onde "os aspectos biológicos são, quase sempre, utilizados como elementos que comprovariam a naturalização e, portanto gerariam sentença sobre as distinções entre os sexos" (PAIXÃO; SANTOS; RAMOS, 2008, p.
6). Determinadas práticas interpeladas pela noção de diferença entre homens e mulheres decorrem, em parte, de uma "naturalização das diferenças perpassadas por várias instituições responsáveis pela nossa aprendizagem e formação, como, por exemplo, a família e a escola. Dessa forma, reproduzimos esses conceitos como verdades naturais e os trazemos para as relações sociais de nossas vivências" (PAIXÃO; SANTOS; RAMOS, 2008, p. 1)

Taquette, Vilhena e Paula (2004, p. 283, grifo nosso) enfatizam ainda que "o que é ser homem e/ou ser mulher tem suscitado inúmeras interpretações em diversos campos do saber. A atitude dos homens e das mulheres está intimamente ligada às representações simbólicas de masculinidade e feminilidade que se constroem historicamente". A juventude, período importante na construção dessas representações simbólicas, "é caracterizada por um processo de transição para a vida adulta e nesse percurso as mudanças ocorridas são consubstanciadas por condições sociais muito distintas, como gênero e classe social" (DIAS; AQUINO, 2006, p. 1448). Dias e Aquino (2006) consideram também que essas vivências do cotidiano revelam que desde cedo as mulheres têm a si outorgadas as funções de cuidar da casa e dos irmãos menores, enquanto que para aos homens é reservado o papel das descobertas na rua, ou seja, da vida social.

Essas expectativas naturalizadas de gênero podem ser circunscritoras não apenas das trajetórias, mas das expectativas de futuro, de modo geral. Ao definir o conceito de projeto vital (PV), Damon, Menon e Bronk (2003, p. 53) chama a atenção para entendê-lo como "uma intenção estável e generalizada de alcançar alguma coisa que é ao mesmo tempo significativa para o eu e gera consequências no mundo além do eu'. O projeto vital, desta forma, compreende objetivos que se caracterizam por determinada estabilidade situacional, como uma determinada meta que orienta, estando sujeita a relacionar-se a um intento não necessariamente realizável concretamente, mas como algo que define um senso de direção à vida (DAMON; MENON; BRONK, 2003).

O PV compreende, portanto, um conjunto de concepções do indivíduo, constituídas como "subsistema psicológico principal da pessoa em suas dimensões essenciais da vida" (HERNÁNDEZ, 1995, p. 2, tradução nossa). O PV abrange idealizações sobre o que determinado sujeito espera ser ou realizar, estabelecendo relações com o meio através das possibilidades internas e externas de alcançar suas aspirações. Estes desejos, que se projetam para o futuro como uma visão antecipatória de acontecimentos, têm por base uma realidade construída na interseção das relações que o indivíduo estabelece com o mundo, sendo, portanto, constituídos pelo conjunto complexo de aspectos que estruturam o campo psicossocial (NASCIMENTO, 2006).

Corroborando com esta perspectiva, Lopes de Oliveira, Pinto e Souza (2003), afirmam que as construções de projetos vitais são parte da constituição de um status adulto, e se constituem no cruzamento de diversas ordens, como a mídia e a escolarização, tanto em nível das macropolíticas educacionais, como das micropolíticas das salas de aula de 
escolarização básica. A discussão sobre potencialidades de um PV pode tornar-se ainda mais complexa se, além das questões de gênero obviamente implicadas, a ruralidade for outro marcador identitário a ser considerado.

As temáticas vinculadas ao âmbito rural vêm sendo trabalhadas por estudiosos de áreas variadas, cada vez mais com o intuito de desnaturalizar a usual dicotomia entre o que é rural e o que é urbano, ou a relação centro/ periferia. Os primeiros estudos adotaram essa perspectiva dicotômica, comum à Modernidade, como a definição de Tönnies (1947[1887]), que cria os conceitos de comunidade (Gemeinschaft) e sociedade (Gelleschaft) para compreender os fenômenos que se passavam, e diferenciavam a vida no espaço urbano e rural. As características que constituiriam o rural estariam vinculadas à noção de comunidade, que designaria um espaço dotado de coesão emocional, profundidade, continuidade, conservadorismo, etc. Enquanto isso, o urbano, que corresponderia à compreensão de sociedade, seria caracterizado pela ideia de impessoalidade, relações contratuais e a preponderância do racionalismo. Tal dicotomia viria a classificar o espaço rural como aquilo que não é urbano, sendo definido, por exemplo, a partir de carências e não de suas características (MARQUES, 2002).

As revisões de ideias tradicionais de ruralidade, no sentido de aproximar-se mais de uma concepção contemporânea, exigem pensar o ser humano em suas diversas articulações discursivas para além de um espaço geográfico ou econômico. Entende-se, com essas formulações, que a apropriação de um determinado espaço se constitui a partir da significação que determinada pessoa estabelece para si e para os outros (SOUZA, PEDON; 2007). Nesse sentido, Maria José Carneiro (2008) também se recusa a pensar através de uma relação binária, na qual o rural é concebido como oposto ao urbano. Carneiro (2008) defende orientar o foco de análise para os agentes sociais que configuram a ruralidade, em oposição à analise reificada de um espaço geográfico, o que possibilitaria, por exemplo, que a distinção entre "cidade" e "comunidade rural" ou "urbano" e "rural" desapareça ou torne-se inútil como questão sociológica.

As pesquisas referentes ao meio rural são especialmente escassas na Psicologia (ALBUQUERQUE, 2002), área fortemente identificada com os valores da Modernidade, que desde os seus primórdios priorizou a compreensão dos fenômenos humanos a partir do referente urbano. Mesmo representando número expressivo da população brasileira (totalizando 29.829.995 habitantes - IBGE, 2010), as pessoas e os modos de vida do meio rural são ausência destacada na produção psicológica brasileira. A "subjetividade rural" é pouco explorada, em comparação com o que ocorre em relação ao meio urbano. Em recente análise da produção junto à base de dados Psycoinfo encontraram-se somente 65 artigos que se destinavam à população do meio rural. Quando a análise das publicações nacionais é refinada para a mulher do campo

Fractal, Rev. Psicol., v. 27 - n. 3, p. 247-255, 2015 os números também são pouco expressivos, corroborando com a já anunciada ausência de estudos (LANDINI; BENÍTEZ; MURTAGH, 2010).

Os autores e autoras que, na contramão, voltaram suas pesquisas para as mulheres do campo revelam peculiaridades desse contexto plural. Salienta-se que o dossiê da Revista Estudos Feministas, denominado as "Agricultoras Rurais do sul do Brasil", publicado no ano de 2004, é um dos poucos materiais que aprofunda as relações de gênero com mulheres do meio rural. Um exemplo é o trabalho de Karam (2004), que ao estudar as mulheres que trabalham com agricultura orgânica demonstra que estas foram precursoras nesta modalidade de cultivo. Além do caráter inovador de produção para a região, destacou-se o incentivo por parte dos pais para que as filhas se mantivessem na escola, isso com vistas à possibilidade de outras colocações que a educação propiciaria.

Outras análises no eixo gênero e espaço rural, como a de Stropasolas (2004) acerca das representações do casamento para jovens, homens e mulheres deste âmbito, especificamente oriundos de famílias da região colonial do Rio Grande do Sul, verificam que principalmente as mulheres se questionam sobre os moldes de casamento que lhe são fornecidos neste contexto.

Ainda que as relações de gênero tomem configurações distintas nas diversas regiões que compõem o cenário do interior brasileiro, predominam nas pesquisas referenciadas a desigualdade nestas relações. O presente relato se propõe, a partir da compreensão que as construções simbólicas de gênero também interferem no cotidiano das jovens mulheres do meio rural, evocar (nas narrativas e fotos que sedimentaram o corpus de análise) aqueles discursos que interpelam os projetos de vida dessas jovens. A seguir os passos metodológicos que posteriormente possibilitaram algumas discussões nesse sentido são apresentados.

\section{Método}

Este estudo teve um caráter qualitativo, onde se enfatizaram discursos sociais através de entrevistas e produções fotográficas, ambas de caráter biográfico, das participantes. A coleta dos dados foi realizada através de entrevistas narrativas (BAUER; GASKELL, 2002; YOKOY; LOPES DE OLIVEIRA, 2008; ARAUJO; SPERB, 2009), guiadas aos atravessamentos de gênero, contexto, família e ruralidade na significação de projetos vitais. As entrevistas ocorreram em dois tempos. No primeiro foram contempladas perguntas que demonstrassem a trajetória delas até aquele instante. Ao final dessa primeira entrevista eram entregues câmeras fotográficas descartáveis e uma lista com itens que deveriam ser representados através dessa ferramenta. Portanto, a segunda entrevista contou com as fotografias como guia para compreensão dos processos do cotidiano e representações acerca do mundo físico e simbólico em que estavam inseridas.

As participantes da pesquisa, 48 jovens de 14 a 19 anos, foram contatadas através de escolas públicas da zona rural de municípios do interior do Rio Grande do Sul. Além de contar com o aval de tais instituições e dos 
responsáveis pelas jovens, o critério de inclusão foi que as alunas estivessem matriculadas em escolas rurais ou que fossem moradoras da zona rural dos municípios. ${ }^{1}$ Todas as jovens convidadas acederam em participar, ainda que cinco delas acabassem desistindo no percurso. As que participaram de todas as etapas por vezes mostravam maior ou menor dificuldade em falar sobre alguns temas - como a vida sexual, por exemplo -, mas muitas manifestaram sua surpresa e contentamento em serem ouvidas, ou convidadas a refletir pela primeira vez sobre muitos desses aspectos. Foi fundamental nesse processo de coleta o apoio logístico das escolas, que nos enviavam as máquinas para revelação. Evidentemente se assume o viés de desejabilidade que essa estratégia pode ter causado entre as participantes, mas, sem tal operação, a coleta seria bastante mais complicada.

Antes da realização da segunda entrevista, as participantes receberam as máquinas fotográficas para registrar, na ordem que lhes parecesse melhor, os elementos visuais que considerassem significativos sobre suas vidas, dentro das temáticas estipuladas. A lista com as temáticas tinha os seguintes itens: escola, família, pai, mãe, futuro, passado, ser mulher, ser homem, educação, casamento, profissão, sonho, lazer, professor, cidade, interior, comunidade, foto própria. Tal aproximação metodológica, focada na produção de fotografias, possibilitou abordagens diferenciadas do modelo de entrevista tradicional. Esta perspectiva metodológica obedeceu aos moldes defendidos por Maurente e Tittoni (2007) e Pizzinato, Cé e Oliveira-Machado (2012), no qual a fotografia funciona otimizando aspectos de expressão não tão diretamente apreendidos pelo discurso verbal e instrumentalizando o processo de construção da entrevista narrativa. Dentre o material coletado com as jovens, obtivemos 430 fotografias. Como as fotografias constituem peças de um quebra-cabeça significadas coerentemente apenas se analisadas junto com as entrevistas que as envolvem, nem todas foram significadas de forma clara pela equipe. Ainda assim, algumas foram mais ricas nas discussões de outros aspectos que não os que se propõem na presente análise (como a vida escolar, por exemplo). Para darmos um caráter mais narrativo nas discussões das categorias previamente propostas para a análise, ilustraremos com elementos das entrevistas e fotografias de algumas jovens - mais claramente quatro - que sintetizaram de maneira mais objetiva os elementos trazidos pelas demais participantes.

Segundo Banks (2009), a produção de narrativas visuais se define como uma organização intencional de informações, dessa maneira, os materiais podem ser entendidos como estruturas comunicativas. Nesse sentido foi proposto que, além de elaborar considerações sobre as fotografias isoladamente, o entrevistado estabelecesse sentidos para a construção da série fotográfica como um todo, estabelecendo ordens de importância, cronológica, etc. para sua produção. Este método de produção fotográfica parece despertar envolvimento e uma postura ativa nas participantes da pesquisa. De acordo com Neiva-Silva ${ }^{1} \mathrm{O}$ projeto de pesquisa teve aprovação junto ao Conselho de Ética da Pontifícia Universidade Católica do Rio Grande do Sul e está registrado sob o número $11 / 05325$. e Koller (2002), há um alto índice de retorno dos participantes em pesquisas materializáveis através da produção de imagens. É uma perspectiva de pesquisa que ultrapassa as limitações da linguagem verbal e possibilita um exercício simbólico-contextual de autorreflexão, por vezes dificultado somente com os recursos discursivos da fala.

\section{Discussão dos resultados}

As narrativas apresentadas pelas entrevistadas abrangem diversos pontos acerca dos seus cotidianos e daqueles que dele fazem parte. Um repertório discursivo, tanto oral quanto visual, sobre relações de gênero perpassou muitas das narrativas, tanto na primeira entrevista, na produção das fotos, como na segunda entrevista, posterior à produção das imagens. Os projetos vitais mostraram-se circunscritos, ora a encapsulamentos das trajetórias educacionais e comunitárias, ora a subversões da ordem das relações familiares e de gênero. A visão dessas jovens acerca da figura do pai, da mãe, do que é ser homem ou mulher, entre outros, demonstraram articulações que pendem contextualmente às perspectivas tradicionais de gênero, ainda que apresentem pontos de fuga possíveis.

Em suas falas, evidencia-se que o modelo patriarcal persiste, ainda que tenha tomado formas diferentes na atualidade - nem tão densas e nem tão impermeáveis. Ainda que resquícios importantes deste modelo cultural tradicional estejam presentes nas relações entre homens e mulheres do campo, parece que as narrativas das entrevistadas demonstram possibilidades de empoderamento feminino apesar do patriarcado.

Em uma das verbalizações onde analisava a fotografia por ela tirada, a participante comenta:

O meu pai eu "tirei" assim dele trabalhando, essas coisas assim, sabe, porque ele trabalha bastante e eu tirei dele assim. É, geralmente, tem pai assim que não é muito [...] demonstra muito carinho assim, mas no fundo ele tem. Um pai mesmo pra ser, deve ser carinhoso, essas coisas assim. Tem. Geralmente mãe é muito mais carinhosa que pai. Dá mais conselhos, essas coisas assim, eu acho que é isso, é a base de tudo (Marisa, ${ }^{2} 16$ anos).

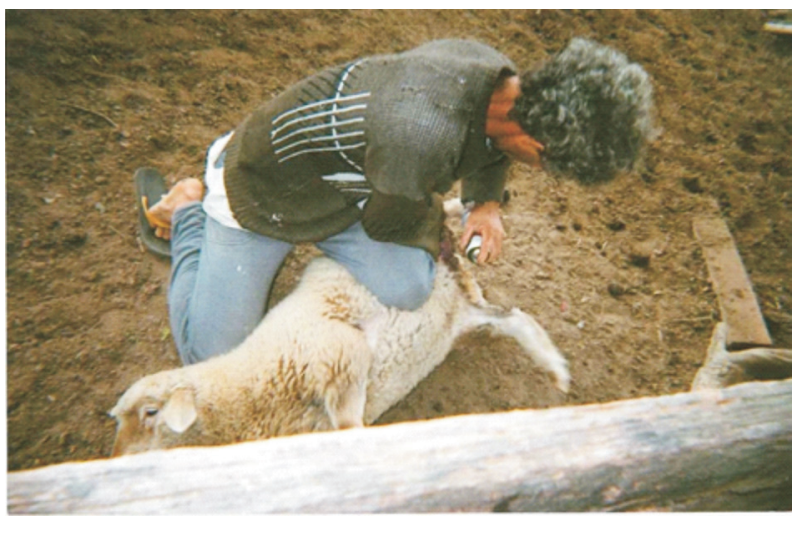

$$
\text { Figura 1. "Pai" }
$$

Para esta participante, particularmente, ao longo das entrevistas a noção de trabalho apresentou-se intrinsecamente relacionada com a ideia de do exercício de atividades no espaço público, e com a figura masculina quando

${ }^{2}$ Os nomes usados para ilustrar as falas das participantes são todos fictícios. 
o trabalho é realizado dentro das propriedades da família - os fazeres dentro da casa propriamente, quando citados, são ligados à figura materna ou feminina de forma geral e não são identificados como "trabalho". Entretanto, esta fala contém um dissenso. A relação de naturalização do homem ao trabalho público poderia remeter exclusivamente a uma perspectiva tradicional - em que o homem é relacionado ao trabalho considerado produtivo, formal e remunerável e a mulher ao trabalho reprodutivo e de cuidado, como algo da natureza existencial feminina. Entretanto, para esta jovem, no momento em questão, a característica "trabalhadora" do pai é herdada por ela. Apresenta-se na narrativa de Marisa a proximidade de identificação com o "gosto pelo trabalho", que em outros momentos das falas denota ser concebido como o fazer exercido no espaço público, ainda que em fazeres associados ao campo do cuidado - como a ideia de ser professora, enfermeira ou médica veterinária.

É interessante notar que a categoria trabalho tenha se mostrado suscetível a variações narrativas e possibilidades de identificação, visto que historicamente é uma categoria que possibilitou às mulheres inserção no espaço público que foi tradicionalmente masculino. Essas articulações não se deram sem conflitos, e mostram-se presentes nas narrativas de Marisa e de outras jovens, corroborando com discussões sobre a história das mulheres, que questionam a qualidade dessa inserção e as armadilhas que acompanham as possibilidades para as mulheres dentro do capitalismo patriarcal (DIOGO; COUTINHO, 2006).

Ao assumir posições de questionamento, as mulheres do âmbito rural tensionam o cerne da agricultura naquele espaço, ou seja, a família. Aparentemente o trabalho e a manutenção da propriedade na agricultura familiar são o principal aglutinador identitário de seus membros, mesmo que sejam profundamente assimétricos em relação às expectativas de gênero. A disparidade entre os papéis atribuídos ao homem e à mulher repercute nas trajetórias de vida destes: enquanto que os homens ainda detêm poder decisório sobre os rumos da produção e são vistos como herdeiros naturais da propriedade e na continuidade do trabalho exercido, as mulheres, por sua vez, estão ausentes dessas discussões e tendem a buscar novos rumos em suas vidas, inclusive no que diz respeito ao casamento ou à formação educacional. A escolaridade se pronuncia como fator importante nesse rompimento com o modelo de relacionamento tradicional, assim as mulheres apresentam maior escolaridade que os homens, e convertem esse aspecto de suas vidas como potencializador de outros rumos profissionais e de relacionamento, vinculados em sua maioria a experiências na cidade (STROPASOLAS, 2004).

Os dados da migração rural-urbana corroboram as perspectivas levantadas por Stropasolas (2004). Partindo de análises quantitativas e qualitativas, Brumer (2004) também conclui que as mulheres migram para as cidades acentuadamente mais que os homens. A causa desse processo migratório de mulheres estaria, entre outros, justificado pelas desigualdades de gênero associadas ao trabalho e à propriedade que estas ainda enfrentam. Embora alguns produtos, como ovos, queijo, nata, por exemplo, sejam vendidos pelas mulheres, e os recursos fiquem sob sua gerência, se nota que aqueles produtos que envolvem maior valor são negociados pelos homens, reforçando a ideia de trabalho reprodutivo feminino, ou seja, de suporte ao masculino.

Voltando mais uma vez à fala de Marisa, a jovem pende entre a figura paterna ligada a um distanciamento afetivo e intrinsecamente ao trabalho, e um discurso que parece ser de ampliação destas funções, referente à afeição e cuidado - mas geralmente suposto, não claramente explicitado. Segundo a referida participante, um pai - para ser pai - deve proteger e cuidar, mesmo que não demonstre afetividade. De outro lado a mãe, reconhecidamente mais carinhosa, é ligada aos conselhos e à manutenção de conversas e contato afetivo. Estas características denotam evidente conteúdo histórico de dominação das mulheres - em que uma suposta atenção natural aos outros seria intrínseca a estas - entretanto, as aspirações por estudo e exercício profissional para esta jovem, assim como a característica herdada do pai de "gosto pelo trabalho", parecem ressaltar possibilidades de articulações a serem exploradas.

A história das mulheres, como nos lembra Torrão Filho (2005), tornou-se sinônimo das memórias sociais atribuídas aos aspectos privados, e da reprodução dos saberes do espaço privado. Da mesma forma, o reconhecimento do espaço público como espaço masculino, ligado à produção e à política, corrobora o processo de legitimação de discursos que mantêm relações binárias e reducionistas de interação social. Entretanto é importante notar as possibilidades criativas evidentes em muitas das narrativas, que tencionam essa composição histórica e social do espaço privado da casa como única esfera de atuação feminina.

Mesmo nas categorias pai e ser homem, a articulação com trabalho e gênero não se apresentou estática. Ao passo que a figura do pai/homem mostrou-se intrinsecamente relacionada ao trabalho formal, sofreram variações valorativas no que concerne a aquele que produz e trabalha "adequadamente" - o que supõe uma carga de trabalho dito produtivo grande - e aquele que se aproxima da vagabundagem e do risco de não ser um homem e pai desejável. Da mesma forma, as categorias relacionadas a ser mulher e mãe mostraram-se com certas variações, mas mais convergentes no que concerne à maternidade, casamento e trabalho reprodutivo quando interseccionadas com o fator geracional. Mães e avós foram referidas e representadas nas fotografias principalmente direcionadas sob estes três eixos, no entanto as jovens - ao passo que mostram diversas ligações com estas temáticas - parecem variar mais do que a imagem que construíram de suas mães e avós.

Embora no que se refere à temática "trabalho" se vislumbrem maiores articulações e possibilidades para as jovens, na temática sexualidade isso não foi evidente. Ainda que, como foi ressaltado anteriormente, a mãe seja referência na relação com o cuidado, e esteja mais próxi- 
ma das filhas no cotidiano, este assunto se constitui como "tabu" e é repassado para o âmbito escolar: "Ela acha que é bom porque em casa ela tem um pouco de vergonha de falar disso, ela acha que é bom que ensinem no colégio". Neste sentido, a figura da mãe compreende uma fonte importante nas narrativas no que se refere a aspectos de intimidade e troca, frequentemente sendo referidas como "melhores amigas", entretanto não sem pontos de embate. A dificuldade de tratar a temática da sexualidade é um exemplo destas problemáticas mãe/filha, inclusive da própria concepção de sexualidade.

Além da disponibilidade de refletir sobre este aspecto de suas vidas, vemos que ela se intersecciona com diversos elementos cotidianos. As possibilidades de exercício da sexualidade presentes nas narrativas evidenciam o cerceamento de algumas atividades por parte das jovens, por vezes privilegiando o trânsito pelos espaços privados em detrimento da circulação pelo público. A narrativa de uma das participantes demonstra dois destes aspectos dialógicos, a mãe como conselheira e o medo da exposição social:

ela tem medo que eu vou atravessar a rua e venha um carro e me atropele, ah, que aconteça algum acidente e coisa assim ou que eu faça alguma "cagada". (risos) Bah, ah, sair assim, como ela diz, ah, ela fala: pra mim vocês são diferente, agora não é mais namorar, é só ficar e coisa, e ai ela tem medo disso. Ela fala que ficar já é diferente, ficar é ir pra cama" (Susana, 15 anos).

Nesta fala fica evidente que para a participante e sua mãe os riscos do espaço público são muitos, ou ao menos de impacto social. Nota-se, entretanto, o fato de ser da mãe a posição de orientação à filha no que concerne à sua conduta, e à noção do sexo como risco equivalente a um acidente ou atropelamento. Este perigo relacionado ao sexo e ao exercício da sexualidade se mostrou intrinsecamente relacionado aos itinerários territoriais das jovens. Nesse sentido, foi interessante notar nas narrativas das jovens os seus locais de circulação, assim como as condições sob as quais esta acontece.

De maneira geral o discurso frente à ruralidade como de um lugar calmo, composto por pessoas afetivas que baseiam a sua relação no cuidado e respeito ao próximo, descrição similar à de Tönnies (1947[1887]) quando discute seu conceito de comunidade (Gemeinschaft). Em contraposição, a cidade, e os seus integrantes, é representada no discurso como sendo o local marcado pela impessoalidade e vínculos com base nos interesses, na mesma linha do conceito de sociedade (Gelleschaft) de Tönnies. Assim, partindo do princípio de a comunidade rural ser concebida como espaço calmo, constituída de pessoas respeitadoras e preocupadas com aqueles que fazem parte do seu grupo, ou seja, um local que não ofereceria perigos - estas falas não seriam tão coerentes. Entretanto, percebe-se pela narrativa de muitas dessas jovens que alguns locais como os bailesffestas só podem ser acessados quando estão na presença de um familiar, especialmente um homem (pai, irmãos) protetor, pois poderiam propiciar experiências de vivência sexual ou afetiva que comprometeriam um futuro comunitário digno:

Ele não gosta que eu saia com ele, ele gosta de proteger eu, a minha irmã e a minha mãe. A minha irmã principalmente, quando ela bota uma roupa mais justa, por exemplo, ele já manda trocar. Parece que "ai, ele mandou ela trocar”, mas uma roupa justa demais, todo mundo vai te olhar, todo mundo vai falar coisas de ti, inventar coisas de ti (Carla, 16 anos).

Ficaram evidentes certos contrastes, quando relacionados à autonomia das jovens, no que concerne aos locais e aos cuidados necessários para se movimentar neles. A "proteção" que eles fornecem ao acompanhar as jovens a estes locais refere-se não a cuidar de um perigo da ordem da violência física, mas sim dos riscos que espreitam a ordem moral, em outras palavras, da concepção de honra que permeia as relações vigentes naquelas localidades:

Ah, ela disse que se algum dia eu fizer essa "cagada", a primeira pessoa que tem que ficar sabendo é ela, né, porque se ela ficar sabendo pela boca dos outros vai ser mais complicado. É, porque daí começa as fofocas" (Natália, 15 anos)

Ainda no âmbito da contenção dos movimentos dessas jovens se destacam outros limitadores de socialização, com um viés de controle do masculino sobre o feminino, reproduzindo a ideia de que o último seria naturalmente vulnerável e corruptível:

[...] o pai não gosta que eu saia muito de casa assim, essas coisas, tem muitos jogos da escola fora, na cidade, o pai não gosta. A mãe já gosta, porque ela diz que, se eu gusto [...] Aí o pai: "Eu não gosto!'. Aí ele já fica meio de caras assim, mas ele deixa. Não sei, ele diz assim: "Por causa que tu vai ficar sozinha lá, porque eu não gusto", e eu digo: Pai, tem um professor [...] - "Mas igual tu vai ficar sozinha, não vai está nem com o teu pai nem com a tua mãe lá" (risos) (Veridiana, 16 anos).

Algumas verbalizações de resistência a esse contexto aparecem no decorrer das narrativas, mas se evidenciam de maneira mais aguda quando o casamento surge entre os planejamentos futuros. A alternância entre modelos tradicionais de união conjugal e versões mais alternativas é veiculada pela maioria das jovens, demonstrando abertura a outras formas de conceber relacionamentos conjugais de longa duração, ainda que prevaleça o arranjo tradicional:

Ah, porque toda mulher sonha em entrar na igreja, de vestido. Mas eu penso [...] não que eu pense pouco, mas eu penso: "ah, pra que tudo fazer isso se a gente pode ser feliz assim", os dois se unem e podem ser felizes, fazer a festa da gente, né? Então eu penso: "pra mim tanto faz, se for pra me casar em uma igreja eu caso, se não eu fico feliz igual, né?"' (Gabriela, 17 anos).

As alternativas ao modelo hegemônico de conjugalidade presentes nas narrativas, também podem ser percebidas na posição temporal que o casamento ocupa em suas vidas, sendo considerado pela maioria como fase posterior à conclusão dos estudos e conquista de espaço no mercado de trabalho. Um exemplo disso é outro item que se destaca nas narrativas construídas a partir da relação casamento- 
-trabalho-estudos - a preponderância do uso da palavra "independência", ou de expressões ligadas a ela como "não quero depender de ninguém", que se fazem presentes nos planos e dirigem suas perspectivas de futuro:

Eu preferia tá trabalhando pra depois me casar, eu me formar, eu tá bem de vida pra depois me casar, porque eu não quero que alguém me sustente, senão eu vou me sentir uma pessoa que não vale nada, sem valor, que tá só ali pra cuidar dos filhos e arrumar a casa. Eu quero ter esse gostinho de como é trabalhar e sustentar a casa. (Caroline, 14 anos).

Essa noção de independência presente nas narrativas emerge tanto em conjunto com os planos de mesclarem experiências da vida no campo com oportunidades da cidade, como na concepção de construção da vida conjugal. Entretanto, mesmo que rompendo com algumas amarras tradicionais, parte das jovens ainda necessita de um projeto de vida que inclua um homem (marido, companheiro) como "avalista". Este aspecto nos remete ao conceito de "fiador" do discurso (MAINGUENEAU, 2008), e permite pensar certos paralelos com a figura masculina nos projetos de vida de muitas jovens - em possíveis personificações dos homens como pessoas com o poder de validar aspectos da vida das mulheres num sistema marcado por hierarquias. Nesse sentido - ao passo que as posições em relação a casamento, vida conjugal e organização de funções no âmbito familiar subvertem alguns princípios patriarcais tradicionais - a ideia de casamento, de constituição de uma família heteronormativa, e a idealização da maternidade continuam presentes de forma importante.

A interface com a maternidade, em especial, dá indicativos importantes sobre a noção de papéis de gênero. As interpretações das jovens sobre ser mulher estiveram intrinsecamente relacionadas ao exercício da maternidade que - se demonstra algumas subversões quanto da possibilidade de alternar o momento de vida escolhido como mais apropriado para tanto - supõe a sua existência como uma etapa vital a ser concluída. Neste mesmo âmbito, vemos que a compreensão explícita do que é ser homem e mulher aparece vinculada às características biológicas, mas prepondera a escolha de marcadores culturais para compor a especificidade de cada um destes: "O corpo é diferente, o jeito de caminhar e de falar é diferente, a mulher é mais delicada" (Luísa, 16 anos). Os estereótipos corporais sobre o ser mulher se mostraram presentes principalmente no desejo de exercer uma feminilidade intrinsecamente relacionada a um corpo e comportamento que envolvia sensualidade, cuidado, e comportamentos "adequados":

Uma vez quando eu tinha uns 7 anos, eu queria ser modelo fotográfica, depois de assistir TV, eu sempre via as modelos lá e eu queria ser como elas. Mas tinha umas coisas tipo anorexia e coisas assim, dai eu comecei a ficar com medo, dai eu não quis mais ser isso, só pediatra (Francine, 16 anos).

A noção de homem ainda é bastante atrelada ao trabalho de visibilidade social, a força física e poder de compra, enquanto isso a mulher é entendida como vaidosa, meiga, carinhosa e com menos poder de compra.
As duas fotos que seguem, por exemplo, demonstram essa relação de maneira bastante explícita: A construção da definição da imagem fotográfica de homem conta com uma bebida espumante, chave de carro, carteira com nota de 50 reais à vista, um perfume e revista com uma mulher em pose sensual e subtítulos como "Menu sexual”. Já a imagem representando a mulher é composta por diversos tipos de maquiagens e bijuterias, além de apenas 14 reais junto à carteira.

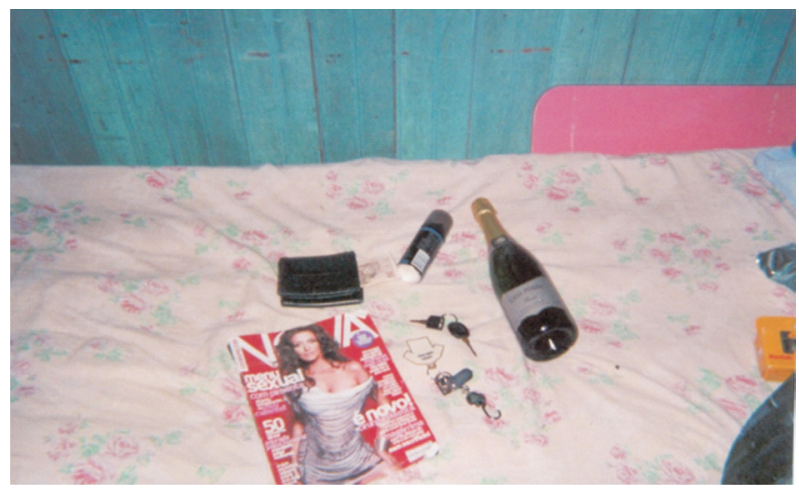

Figura 2. "Ser homem"

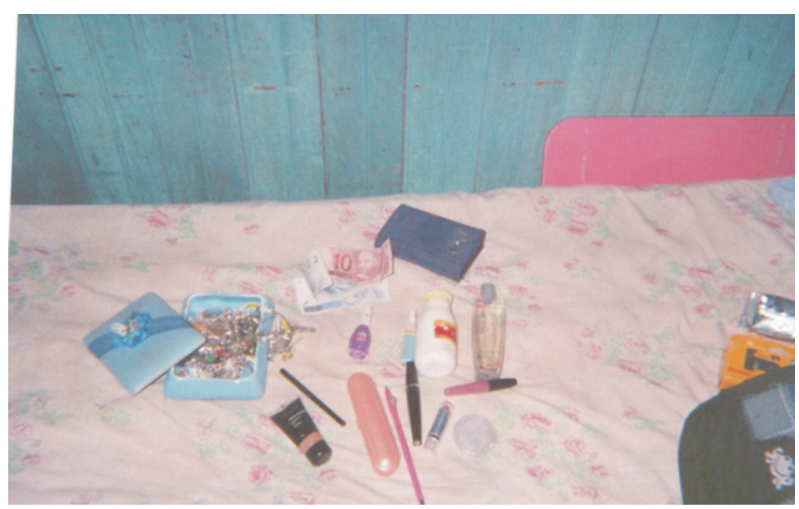

Figura 3. "Ser mulher"

A naturalização das concepções estereotipadas de gênero - ilustradas aqui - podem circunscrever diversos aspectos das identidades dessas jovens. A construção simbólica através de posições de gênero compreendidas como naturalmente definidoras do que é das mulheres ou dos homens tende a refletir sobre as escolhas no campo do projeto vital. Muitas das representações das jovens acerca da sua realidade e projetos vitais, a exemplo destas fotos, nos mostram formas contemporâneas de exercer a dominação masculina - e que nos remetem constantemente a fatores como, por exemplo, a noção da renda produzida pelo trabalho (noção que nos discursos não contempla as atividades no espaço privado) exercido pela mulher como dinheiro supérfluo. Tal normatividade de gênero pode ser um indicativo e ter reflexo nas escolhas futuras dessas jovens em diversos aspectos, como a carreira que gostariam de seguir, as escolhas de conjugalidade, o exercício da sexualidade e projetos vitais de forma geral.

No que concerne à profissão, especificamente, vemos que a preponderância pela eleição de profissões em que se exerça a função de cuidadora, ou que estão historicamente situadas como sendo exercidas por mulheres, revela para além de uma escolha a restrição simbólica que 
cerceia a vida das mulheres (TORRÃO FILHO, 2005), e circunscreve suas escolhas pelo viés da naturalização do potencial de cuidado como o maior definidor do feminino, tanto no profissional, quanto no pessoal. Entretanto, fica evidente como, ao mesmo tempo em que cerceia aspectos das vidas destas jovens, a escolha das profissões e das experiências universitárias como parte dos seus projetos vitais demonstra um alargamento nas possibilidades de vida das mulheres - e que deve ser potencializado como forma de desnaturalizar estas concepções de dominação masculina.

\section{Considerações Finais}

Os resultados desta pesquisa indicam alternâncias dialógicas nas narrativas - entre aspectos discursivos mais tradicionais, arraigados nas leituras naturalizadas das expectativas e das relações de gênero, e perspectivas mais subversivas, mas sempre em contato umas com as outras - operando como contrapalavras das vozes discursivas majoritárias. Discursos de resistência ou contestação que sempre precisam ser justificados. Por vezes as possibilidades de exercício da feminilidade em espaços não tradicionalmente reservados às mulheres - do trabalho considerado produtivo socialmente e do exercício com autonomia no espaço público, por exemplo - muda conforme as narrativas pendem para as figuras das mães e avós. Para estas, em especial, as discussões em relação a trabalho e exercícios sociais parece mais restrito, o que nos faz atentar para possíveis trabalhos que enfoquem intersecções entre questões geracionais e de gênero nas narrativas de jovens do campo.

Compreendeu-se que as categorias didaticamente estabelecidas previamente para a proposta de pesquisa não se mostraram encapsuladas, mas sim divergiam e convergiam contextualmente ao longo da criação narrativa das jovens. Nesse sentido, vemos que questões relacionadas a projeto vital faziam emergir as noções e possibilidades de trabalho, sexualidade, gênero, e da relação com espaço rural/urbano de maneira dialógica, mesmo que mostrando mais possibilidades de interlocução (energia e gravidade narrativa) em algumas do que em outras - a exemplo da expressiva maior possibilidade de visualização em relação ao futuro no que concerne a trabalho e educação, em relação ao exercício da sexualidade.

Esta conjuntura nos faz atentar para as possibilidades de alargamento das discussões no campo da educação, tanto no que se refere ao contexto educacional das jovens e das interlocuções em temáticas como gênero, sexualidade e projetos futuros, como na própria pesquisa acadêmica que não engloba como deveria as especificidades do meio rural brasileiro. Vemos que, ainda que a cultura organize outras possibilidades simbólicas e a sociedade forneça modelos predominantemente orientados a ocupações urbanas e vinculados à escolarização formal, essas possibilidades nem sempre são interpretadas como instrumentalizáveis na construção de novas formas de ser uma jovem mulher do (no) meio rural. A escola exerce impacto expressivo sobre a sociedade, e nas comunidades rurais poderia ser um dos veículos da mudança gradual destes paradigmas naturalizadores de gênero.

\section{Referências}

ALBUQUERQUE, F. J. B. de. Psicologia social e formas de vida rural no Brasil. Psicologia Teoria e Pesquisa, v. 18, n. 1, p. 37-42, 2002.

ARAUJO, G. B. de; SPERB, T. M. Crianças e a construção de limites: narrativas de mães e professoras. Psicologia em Estudo, Maringá, v. 14, n. 1, p. 185-194, 2009.

ARCILA MENDOZA, P. A. et al. Comprensión del significado desde Vygotsky, Bruner y Gergen. Diversitas, v. 6, n. 1, p. 3749, enero-jun. 2010.

BANKS, M. Dados visuais para pesquisa qualitativa. Porto Alegre: Artmed, 2009.

BAUER, M. W.; GASKELL, G. Pesquisa qualitativa com texto, imagem e som: um manual prático. Petrópolis: Vozes, 2002.

BROCKMEIER, J.; HARRÉ, R. Narrativa: problemas e promessas de um paradigma alternativo. Psicologia: Reflexão e Crítica, v. 16, n. 3, p. 525-535, 2003,. Disponível em:<http:// www.scielo.br/pdf/pre/v16n3/v16n3a11.pdf> Acesso em: 16 dez. 2009

BRUMER, A. Gênero e agricultura: a situação da mulher na agricultura do Rio Grande do Sul. Estudos Feministas, Florianópolis, v. 12, n. 1, p. 205-227, jan.-abr. 2004.

CARNEIRO, M. J. "Rural" como categoria de pensamento. Ruris, v. 2, n. 1, p. 9-38, mar. 2008.

DAMON, J.; MENON, P.; BRONK, W. The development of purpose during adolescence. Applied Developmental Science, v. 7, n. 3, 2003.

DIAS, A. B.; AQUINO, E. M. L. Maternidade e paternidade na adolescência: algumas constatações em três cidades do Brasil. Cad. Saúde Pública, Rio de Janeiro, v. 22, n. 7, p. 1447-1458, 2006.

DIOGO, M. F.; COUTINHO, M. C. A dialética da inclusão/ exclusão e o trabalho feminino. Interações, v. 11, n. 21, p. 121142, 2006.

GERGEN, K. J. Realidades y relaciones. Barcelona: Paidós, 1996.

HERMANS, H. J. M. The dialogical self: toward a theory of personal and cultural positioning. Culture \& Psychology, v. 7, p. 243-281, 2001.

HERNÁNDEZ, O. D'A. El Desarrollo Profesional Creador (DPC) como dimensión del proyecto de vida en el ámbito profesional. Revista Cubana de Psicologia, Habana, v. 19, n. 2, 2002.

INSTITUTO BRASILEIRO DE GEOGRAFIA E ESTATÍSTICA. Censo demográfico 2010: características da população e dos domicílios. Disponível em: <http:// biblioteca.ibge.gov.br/visualizacao/periodicos/93/cd_2010 caracteristicas populacao domicilios.pdf $>$. Acesso em: $1 \overline{3}$ mar. 2015.

KARAM, K. F. A mulher na agricultura orgânica e em novas ruralidades. Estudos Feministas, Florianópolis, v. 12, n. 1, p. 303-320, jan.-abr. 2004.

LANDINI, F.; BENITEZ, M. I.; MURTAGH, S. Revisión 
de los trabajos realizados por la psicología sobre pequeños productores agropecuários. Anuario de Investigaciones de la Facultad de Psicología, v. 17, p. 221-229, 2010.

LOPES DE OLIVEIRA, M. C. S. Identidade, narrativa e desenvolvimento na adolescência: uma reflexão crítica. Psicologia em Estudo, Maringá, v. 11, n. 2, p. 427-436, maio/ ago. 2006.

LOPES DE OLIVEIRA, M. C. S.; PINTO, R. G.; SOUZA, A. S. Perspectivas de futuro entre adolescentes: universidade, trabalho e relacionamentos na transição para a vida adulta. Temas em Psicologia, [online], v. 11, n. 1, p. 16-27, 2003. Disponível em: <http://pepsic.bvsalud.org/scielo. php?pid=S1413-389X2003000100003\&script=sci_arttext $>$. Acesso em: 13 mar. 2015.

MAINGUENEAU, D. Cenas de Enunciação. São Paulo: Parábola, 2008.

MARQUES, M. I. M. O conceito de espaço rural em questão. Terra Livre, SãoPaulo, ano 18, n. 19, p. 95-112, 2002.

MAURENTE, V.; TITTONI, J. Imagens como estratégia metodológica em pesquisa: a fotocomposição e outros caminhos possíveis. Psicologia \& Sociedade, Porto Alegre, v. 19, n. 3 p. 33-38, 2007.

NASCIMENTO, I. P. Projeto de vida de adolescentes do ensino médio: um estudo psicossocial sobre suas representações. Imaginário, São Paulo, v. 12, n. 12, p. 55-80, 2006. Disponível em: $\quad<$ http://pepsic.bvsalud.org/scielo.php?script=sci arttext\&pid $=$ S1413-666X2006000100004>. Acesso em: $1 \overline{3}$ mar. 2015.

NEIVA-SILVA, L.; KOLLER, S. H. O uso da fotografia na pesquisa em Psicologia. Estudos de Psicologia, v. 7, n. 2, p. 237-250, 2002.

PAIXÃO, G. P. N.; SANTOS, S. M. P; RAMOS, P. R. Percepções das diferenças de gênero entre adolescentes do município de Juazeiro-BA. UDESC em Ação, Florianópolis, v. 2 n. 1, 2008. Não paginado.

PIZZINATO, A.; CÉ, J. P.; OLIVEIRA-MACHADO, R. de. Apuntes metodológicos para el análisis narrativo de datos visuales en psicología. Diversitas, v. 8, n. 1, p. 13-27, 2012.

SANTOS, M. A.; GOMES, W. B. Self dialógico: teoria e pesquisa. Psicologia em Estudo, Maringá, v. 15, n. 2, p. 353361, 2010.

SOUZA, E. A.; PEDON, N. R. Território e Identidade. Revista Eletrônica da Associação dos Geógrafos Brasileiros, Três Lagoas, v. 1, n. 6, 2007.

STROPASOLAS, V. L. O valor (do) casamento na agricultura familiar. Estudos Feministas, Florianópolis, v. 12, n. 1, p. $253-$ 267, jan.-abr. 2004.

TAQUETTE, S. R.; VILHENA, M. M.; PAULA, M. C. Doenças sexualmente transmissíveis e gênero: um estudo transversal com adolescentes no Rio de Janeiro. Cad. Saúde Pública, Rio de Janeiro, v. 20, n. 1, p. 282-290, jan.-fev. 2004.

TÖNNIES, F. Comunidad y sociedad (1887). Buenos Aires: Losada, 1947.

TORRÃO FILHO, A. Uma questão de gênero: onde o masculino e o feminino se cruzam. Cadernos Pagu, Campinas, n. 24, p. 127-152, 2005.
YOKOY, T.; LOPES DE OLIVEIRA, M. C. S. Trajetórias de desenvolvimento e contextos de subjetivação e institucionalização de adolescentes em cumprimento de medidas socioeducativas. Pesquisas e Práticas Psicossociais, São João Del-Rei, v. 3, n. 1, p. 85-95, 2008.

Recebido em: 6 de abril de 2015 Aceito em: 29 de setembro de 2015 